Clim. Past Discuss., doi:10.5194/cp-2016-116, 2016

Manuscript under review for journal Clim. Past

Published: 30 November 2016

(c) Author(s) 2016. CC-BY 3.0 License.

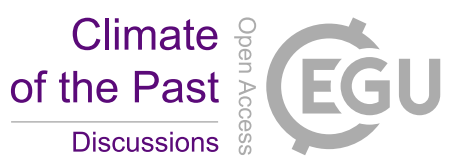

\title{
Constraints on glacier flow from temperature-depth profiles in the ice. Application to EPICA Dome C.
}

\author{
Ignacio Hermoso de Mendoza ${ }^{1}$, Jean-Claude Mareschal ${ }^{1}$, and Hugo Beltrami ${ }^{2,3}$ \\ ${ }^{1}$ Centre de Recherche en Géochimie et en Géodynamique (GEOTOP), Université du Québec à Montréal, Montréal, Québec, \\ Canada \\ ${ }^{2}$ Climate \& Atmospheric Sciences Institute and Department of Earth Sciences, St. Francis Xavier University, Antigonish, \\ Nova Scotia, Canada \\ ${ }^{3}$ Centre pour l'étude et la simulation du climat à l'échelle régionale (ESCER), Université du Québec à Montréal, Montréal, \\ Québec, Canada
}

Correspondence to: Ignacio Hermoso de Mendoza (ihmn.zgz@gmail.com)

\begin{abstract}
.
A one-dimensional (1-D) ice flow and heat conduction model is used to calculate the temperature and heat flux profiles in the ice and to constrain the parameters characterizing the ice flow and the thermal boundary conditions at the Dome $\mathrm{C}$ drilling site in East Antarctica. We use the reconstructions of ice accumulation, glacier height and air surface temperature histories as boundary conditions to calculate the ice temperature profile. The temperature profile also depends on a set of poorly known parameters, the ice velocity profile and magnitude, basal heat flux, and air-ice surfaces temperature coupling. We use Monte Carlo methods to search the parameters' space of the model, compare the model output with the temperature data, and find probability distributions for the unknown parameters. We could not determine the sliding ratio because it has no effect on the thermal profile, but we could constrain the flux function parameter $p$ that determines the velocity profile. We determined the basal heat flux $q_{b}=49.0 \pm 2.7(2 \sigma) \mathrm{mW} \mathrm{m}^{-2}$, almost equal to the apparent value. We found an ice surface velocity of $v_{\text {sur }}=2.6 \pm 1.9(2 \sigma) \mathrm{m} \mathrm{y}^{-1}$ and an air-ice temperature coupling of $0.8 \pm 1.0(2 \sigma) \mathrm{K}$. Our study confirms that the heat flux is low and does not destabilize the ice sheet in east Antarctica.
\end{abstract}

\section{Introduction}

Climate change, as a consequence of human activities, has become a focus of attention of the scientific community. Climate change can be seen as the consequence of an imbalance between the emission and absorption of energy by the planet. Such global energy imbalance generates exchanges of energy among climate subsystems as the Earth follows a path towards a new equilibrium. The cryosphere, and in particular the polar ice sheets, play a key role in the climate system, influencing ocean temperatures, sea level, thermohaline circulation and global albedo, responding to the energy imbalance on time scales ranging from decades to millennia (Clark et al., 1999). Therefore, understanding ice sheet dynamics, controlled by basal heat flux (Oppenheimer, 1998), is of major importance for modelling future climate change. 
Clim. Past Discuss., doi:10.5194/cp-2016-116, 2016

Manuscript under review for journal Clim. Past

Published: 30 November 2016

(c) Author(s) 2016. CC-BY 3.0 License.

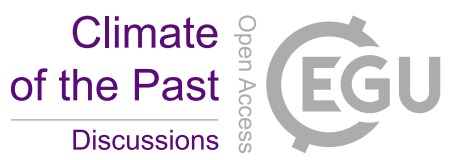

Ice cores from Antarctica and Greenland provide reliable proxy records for the reconstruction of past climate, covering hundreds of thousands of years into the past (Parrenin et al., 2007a; Jouzel et al., 2007). In Greenland, the European Greenland Ice-core Project (GRIP) (Johnsen et al., 1995; Dahl-Jensen et al., 1998) provides data on the last 110ka. In Antarctica, deep ice cores from Dome Fuji (Watanabe et al., 1999), EPICA Dome C (EDC) (Augustin et al., 2004; Jouzel et al., 2007), Vostok (Petit et al., 1999), or EPICA Dronning Maud Land (EDML) (Ruth et al., 2007), allow reconstructions of past climate to 340ka, 800ka, 420ka, and 150ka, respectively.

The analysis of air bubbles trapped in the ice at the time of its formation allows for the reconstruction of past atmospheric concentrations of $\mathrm{CO}_{2}, \mathrm{CH}_{4}$ and $\mathrm{N}_{2} \mathrm{O}$ (e.g. Barnola et al., 1987; Spahni et al., 2005). Past temperatures can be estimated through the analysis of the stable isotope ratios of $\delta^{18} \mathrm{O}$ and deuterium in the ice molecules (Pol et al., 2010), which also yields past snow accumulation rates (Jouzel et al., 2007).

The interpretation of paleoclimatic records from ice cores, as well as the interaction of the ice sheet with the climate system and the solid earth are not straightforward. Ice sheets are complex systems subject to significant variability in their dynamics and structure, which depend on the thermal and mechanical basal boundary conditions (e.g. the basal heat flux and the sliding ratio of the ice sheet) (e.g. Marshall, 2005), and surface conditions (e.g. snow accumulation rates and atmospheric temperatures). Analysis of age versus depth of the ice cores provides some insight on ice flow mechanics (Parrenin et al., 2004, 2007b), through the determination of the ice thinning function, the vertical velocity, as well as the basal melting rate and the sliding ratio. These age depth profiles also provide some constraints on the basal heat flux which is a essential parameter for the dynamics of ice sheet models (Fisher et al., 2015).

High resolution temperature profiles measured in drill holes also retain a record of the time dependent boundary conditions and ice sheet dynamics. These temperature-depth profiles provide another means to determine basal heat flux. In this paper, we use a numerical, one-dimensional (vertical) advective-conductive model which includes the key parameters driving icesheet dynamics. The model is forced by the local histories of atmospheric temperatures, snow precipitation and ice thickness, to determine temperature profiles for the ice-sheet. We then use a Monte Carlo inversion scheme to find set of values of the parameters that fit the observed temperature profile, determine their probability distributions and their most likely values.

We have applied this method to the ice core drilled at EPICA Dome $\mathrm{C}$ in Antarctica, one of the longest ice core records presently available. The temperature profile through the entire thickness of the ice-sheet was measured in the drill hole (Pol et al., 2010). The forcing is provided by the precipitation and atmospheric conditions for the past 800ka that have been reconstructed by analyzing the ice core extracted from the drill hole (Jouzel et al., 2007). The method used in the present study could be applied to any ice temperature profile extending through most of the ice-sheet thickness and provide independent constraints for ice dynamics parameters.

\section{Basic assumptions and equations}

The drilling at the Dome C site ( $\left.75^{\circ} 6^{\prime} 6.35^{\prime \prime} \mathrm{S}, 123^{\circ} 23^{\prime} 42.76^{\prime \prime} \mathrm{E}\right)$, with an ice thickness of $3273 \pm 5 \mathrm{~m}$ (Tabacco et al., 1998), was stopped $\sim 15 \mathrm{~m}$ above bedrock, allowing the measurement of the temperature profile through the entire glacier. The temperature 
Clim. Past Discuss., doi:10.5194/cp-2016-116, 2016

Manuscript under review for journal Clim. Past

Published: 30 November 2016

(c) Author(s) 2016. CC-BY 3.0 License.

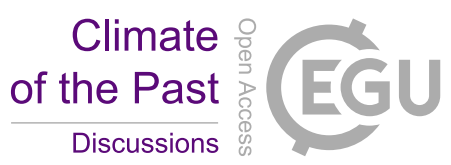

(c) (i)
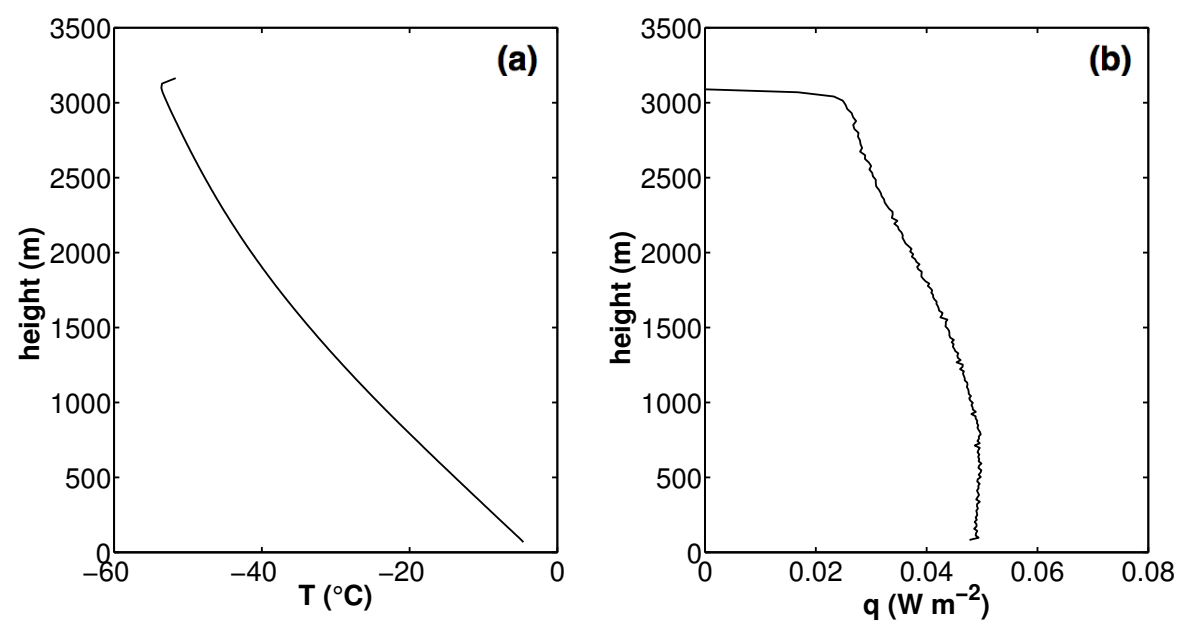

Figure 1. (a): Temperature-depth profile measured in Dome C. (b): Conductive heat flux profile, calculated from the temperature profile by Fourier law with a temperature-dependent thermal conductivity. Heat flux has been truncated at a depth of $225 \mathrm{~m}$ because it is very noisy near the surface of the ice sheet.

profile (Fig. 1) is determined by both the thermal boundary conditions and the ice dynamics which controls heat transport by advection and produces shear heating.

We follow the theory of ice sheet dynamics of Paterson (1994). The ice sheet grows by accumulation of snow at the top, increasing its gravitational potential energy that drives the flow of the ice sheet toward the ocean. Due to basal friction, the velocity of the flow is maximum at the top of the ice sheet and decreases with depth, consequently thinning the ice layers and reducing the height of the glacier. The ice surface is in contact with the air above, absorbing heat from the ice sheet. As heat flows into the glacier from the underlying bedrock, the temperature gradient in the ice is positive downward, which could bring the base to melt. Meltwater reduces basal friction and allows the ice sheet to slide over the bedrock, a movement defined through the sliding parameter $s$, the ratio between the ice horizontal velocity at the base and at the top of the ice (Fig. 2).

We have developed a forward model to simulate the thermal processes that take place in the ice sheet, including both heat diffusion and advection by ice movement, and therefore defined as an advective-conductive model. This model calculates a temperature profile that is determined by heat conduction, the dynamics of the ice sheet, and their boundary conditions.

Ice sheet dynamics is described through the field equations, i.e. the conservation of mass and momentum. The mass conservation for a material of density $\rho$ is:

$15 \frac{\partial \rho}{\partial t}+\vec{\nabla} \cdot(\rho \vec{u})=0$

where $\vec{u}$ is the velocity of the ice.

For an incompressible material $\left(\frac{D \rho}{D t}=0\right)$, a reasonable assumption for ice, the mass conservation equation reduces to:

$\vec{\nabla} \cdot \vec{u}=0$ 
Clim. Past Discuss., doi:10.5194/cp-2016-116, 2016

Manuscript under review for journal Clim. Past

Published: 30 November 2016

(c) Author(s) 2016. CC-BY 3.0 License.

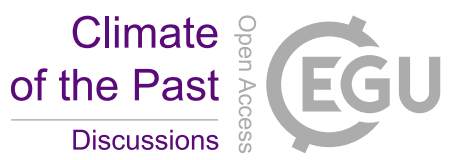

(c) (i)

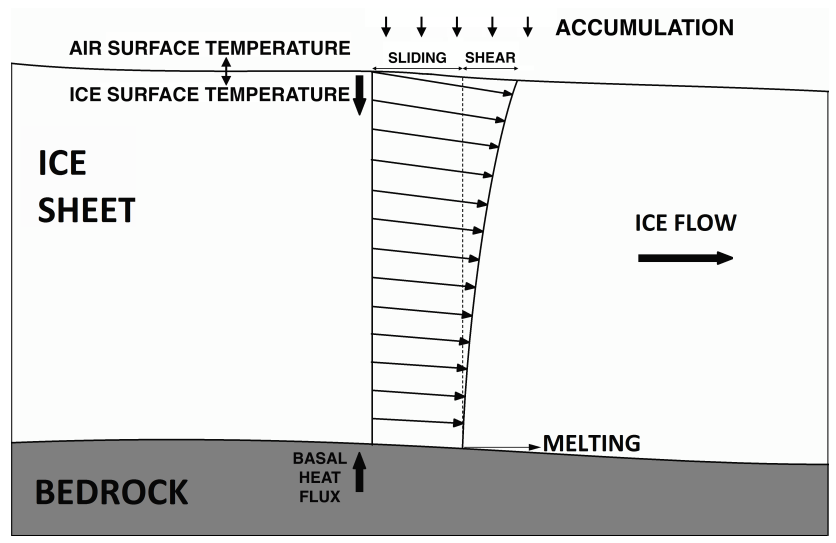

Figure 2. Sketch of flow in an ice sheet. The velocity of ice particles, both vertical and horizontal components, is highest near the surface and decreases at depth. The ice motion thins the ice layers and reduces the height of the glacier, while accumulation of snow at the surface increases its height. Temperature in the ice sheet increases downward, as heat flows out of the bedrock, and melting of ice could happen at the base. The ratio of the horizontal components of velocities at the bottom and at the surface of the ice defines the sliding ratio $s$.

For steady state flow (without acceleration), momentum conservation requires the balance between the body forces acting on the ice volume, i.e., weight $\rho g$ (where $g$ is the acceleration of gravity), and the internal forces described by the stress tensor $\bar{\tau}$ :

$\vec{\nabla} \bar{\tau}+\rho \vec{g}=0$.

5 For ice, the constitutive equation has been established by experimental work (Glen, 1955) and corresponds to non linear viscous rheology. The empirical law that gives the relationship between the strain rate $\dot{\epsilon}$ and the shear stress $\tau$ is known as Glen's law:

$\dot{\epsilon}=A \tau^{n}$,

where $A$ is a temperature-dependent empirical quantity (Paterson, 1994).

At the local scale it is possible to model ice flow in two dimensions by choosing the horizontal axis in the direction of ice flow. In addition, because the size of the ice sheet is much greater than its thickness and variations in crustal heat flux occur on a scale of tens of kilometers (Jaupart and Mareschal, 2015), we can assume that horizontal temperature gradients are negligible and therefore conductive heat flow $q\left(\mathrm{~W} \mathrm{~m}^{-2}\right)$ is vertical and given by Fourier's law in one dimension:

$q=-\lambda \frac{\partial T}{\partial z}$

15 where $\lambda\left(\mathrm{W} \mathrm{m}^{-1} \mathrm{~K}^{-1}\right)$ is the thermal conductivity and $z$ is the vertical coordinate, defined positive upwards with the origin at the base of the ice.

The one dimensional heat equation is (Carslaw and Jaeger, 1959):

$\frac{\partial T}{\partial t}=\kappa \frac{\partial^{2} T}{\partial z^{2}}-u_{z} \frac{\partial T}{\partial z}+\frac{\Omega}{\rho c_{p}}$ 
Clim. Past Discuss., doi:10.5194/cp-2016-116, 2016

Manuscript under review for journal Clim. Past

Published: 30 November 2016

(c) Author(s) 2016. CC-BY 3.0 License.

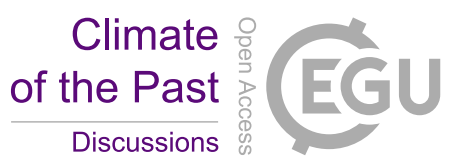

(c) (i)

where $\kappa=\frac{\lambda}{\rho c_{p}}\left(\mathrm{~m}^{2} \mathrm{~s}^{-1}\right)$ is the thermal diffusivity, $\rho=916.2 \mathrm{~kg} \mathrm{~m}^{-1}$ is the ice density, $c_{p}\left(\mathrm{~J} \mathrm{~kg}^{-1} \mathrm{~K}^{-1}\right)$ is the specific heat, and $u_{z}\left(\mathrm{~m} \mathrm{~s}^{-1}\right)$ is the vertical component of the ice velocity. The function $\Omega\left(\mu \mathrm{W} \mathrm{m}^{-3}\right)$ is the rate of heat production per unit volume, due to shear heating. Absorption of latent heat at the base is not included in this term but introduced in the basal heat flux boundary condition.

5 The conductive heat flux profile obtained for Dome C (Fig. 1) can be used to estimate the basal heat flux. From a linear regression of the lowermost $300 \mathrm{~m}$ of the heat flux profile, we obtain an apparent basal heat flux of $q_{b, a p p}=49.4 \pm 1.1 \mathrm{~mW} \mathrm{~m}^{-2}$. However, internal heating caused by shear deformation affects the profile and its effect must be taken into account. Therefore, we consider $q_{b}$ as a free parameter, whose probability distribution is to be evaluated.

\section{Boundaries}

The heat equation requires two boundary conditions. At the top of the ice column, the temperature is the Glacier Surface Temperature (GST). It is obtained directly by assuming a constant offset (see subsection 3.3) from the Surface Air Temperature (SAT) history, which is known from the analysis of the deuterium content of the ice core (Pol et al., 2010), and is in excellent agreement with the reconstruction from $\delta^{18} O$ record (Jouzel et al., 2007). At the bottom, the contact between the ice column and the bedrock, the boundary condition is a fixed and constant basal heat flux $q_{b}$. If the basal temperature reaches the melting point, and basal heat flux is enough to maintain it, the excess heat flux is absorbed as latent heat (see subsection 4.1), and the melting temperature becomes the effective bottom boundary condition.

\subsection{Ice thickness history}

Ice thickness $H$ varied significantly $(3100 \sim 3300 \mathrm{~m})$ during the past $800 \mathrm{ky}$ that we model. We used a prescribed the history of ice thickness, obtained from the linear perturbation model developed in Parrenin et al. (2007b), which is consistent with a large and complex 3-D thermo-mechanical model (Ritz et al., 2001). The ice thickness history obtained from this model is consistently lower $(\sim 350 \mathrm{~m})$ than in that obtained by Parrenin et al. (2007b), but the relative variations of ice thickness are consistent. Therefore, we have used the relative variations of ice thickness defined by this model, using as reference the current ice thickness at Dome $\mathrm{C} H_{0}=3266 \mathrm{~m}$ (Fig. 3). This history of ice thickness was used to calculate $\frac{\partial H}{\partial t}$ dynamically, so that $H$ follows the prescribed history.

\subsection{Surface accumulation and SAT histories}

The accumulation rate $a\left(\mathrm{~m} \mathrm{y}^{-1}\right)$, measured in ice-equivalent units, and the SAT are determined from deuterium content $\Delta \delta D$ (Jouzel, 2007; Pol et al., 2010):

$a=a_{0} \exp \left(\beta \Delta \delta D_{\text {smo }}\right)$,

$\mathrm{SAT}=T_{0}+\alpha \Delta \delta D_{\text {cor }}$, 
Clim. Past Discuss., doi:10.5194/cp-2016-116, 2016

Manuscript under review for journal Clim. Past

Published: 30 November 2016

(c) Author(s) 2016. CC-BY 3.0 License.

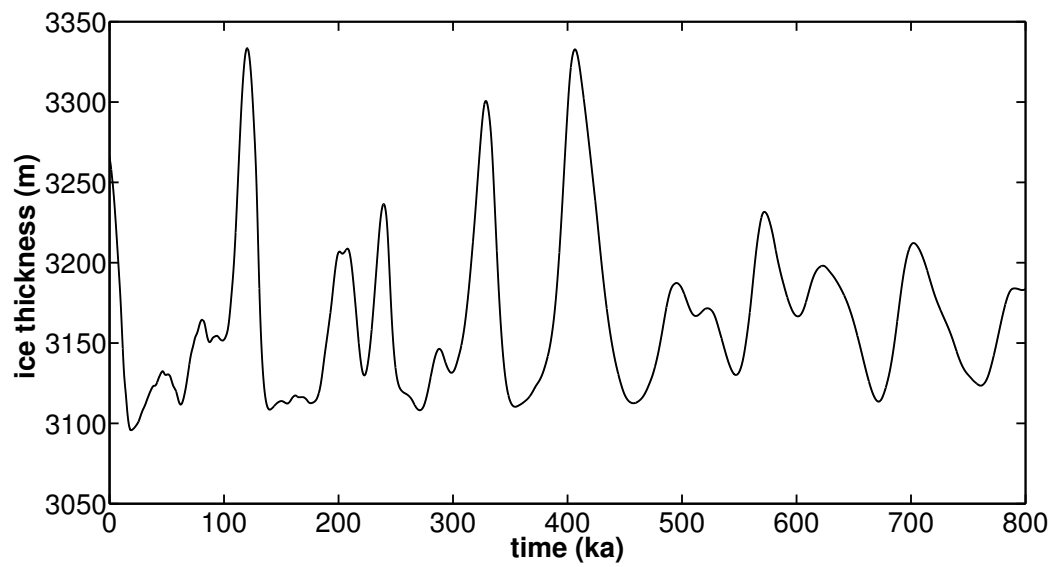

Figure 3. Variations of thickness in Dome C for the last $800 \mathrm{ky}$, simulated with the linear perturbation model developed in Parrenin et al. (2007b).
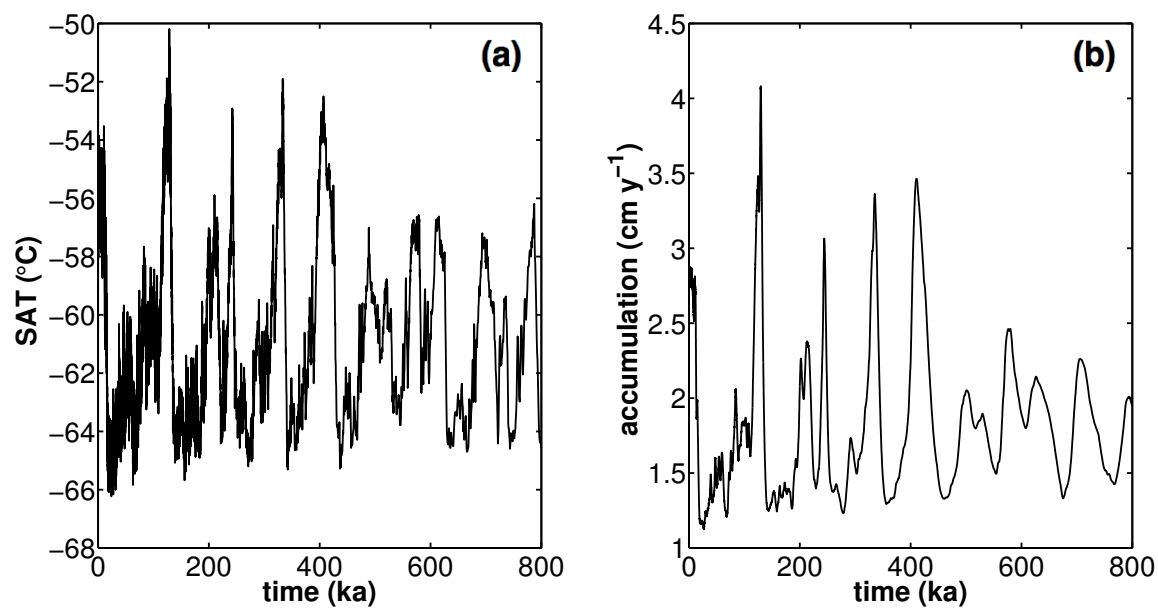

Figure 4. (a): SAT history. (b): Surface accumulation rate (in ice-equivalent units) history.

where $a_{0}$ and $T_{0}$ are the accumulation rate and the surface temperature for a reference deuterium content of $-396.5 \%$ o. $\Delta \delta D_{\text {cor }}$ is the corrected deviation (Lliboutry, 1979) from the current deuterium content of the ice. $\Delta \delta D_{\text {smo }}$ is a 50-year smoothed version of $\Delta \delta D_{\text {cor }}$ because the accumulation rate is only supposed to be related to the deuterium content over a certain time interval (Parrenin et al., 2007b).

5 We use the values $\alpha=1 / 6.04 \mathrm{~K} / \%$ and $T_{0}=215.84 \mathrm{~K}$ for Dome $\mathrm{C}$ of Parrenin et al. (2007b), who determined the values $a_{0}=2.84 \pm 0.03 \mathrm{~cm} \mathrm{y}^{-1}$ and $\beta=0.0156 \pm 0.0012$ by inverse methods. The accumulation rate history and SAT history that result from these values are shown in Fig. 4. 
Clim. Past Discuss., doi:10.5194/cp-2016-116, 2016

Manuscript under review for journal Clim. Past

Published: 30 November 2016

(c) Author(s) 2016. CC-BY 3.0 License.

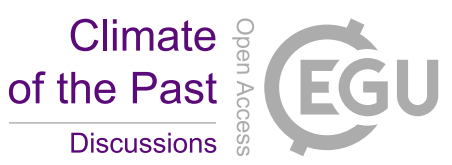

(c) (i)

\subsection{Temperature offset and snow-firn cover}

Accumulation at the surface of the ice column is measured in ice equivalent units, but precipitations are first deposited in the form of snow. Before being transformed in ice, snow passes through an intermediate phase called firn (Arnaud et al., 2000; Goujon et al., 2003). This process is driven mainly by the atmospheric temperatures and the accumulation rates. The density

5 of snow/firn increases gradually with depth, eventually becoming ice. We estimated the average firn density from Dome C data (Arnaud et al., 2000) and modeled the upper $80 \mathrm{~m}$ as firn, with a uniform density $75 \%$ that of ice.

The temperature signal that propagates into the ice column is the GST, a filtered version of the SAT. Measurements at Vostok station over the last 50 years (Vostok, 1958-2016) show that the GST is $\sim 5 \mathrm{~K}$ warmer than the SAT in summer and $\sim-2.5 \mathrm{~K}$ colder in winter. We assume the mean temperature offset $T_{\text {offset }}(\mathrm{K})$ to be time-independent.

$10 T_{\text {offset }}=$ GST - SAT.

Because imprecisions on the estimate of the snow cover of the ice column make $T_{\text {offset }}$ difficult to estimate, it is set as a free parameter restricted within a range $[-2.5 \mathrm{~K}, 5 \mathrm{~K}]$.

\section{Methodology}

\subsection{Basal melting}

15 The forward model calculates dynamically the basal melting rate. When the basal ice layer reaches melting temperature $T_{m}$ (K), the extra incoming energy is used to calculate melting rate $m\left(\mathrm{~m} \mathrm{~s}^{-1}\right)$. The melting temperature depends on the pressure as:

$T_{m}=273.15-\beta_{C C} P$,

where $\beta_{C C}=7.42 \times 10^{-8} \mathrm{~K} \mathrm{~Pa}^{-1}$ is the Clausius-Clapeyron slope and $P(\mathrm{~Pa})$ is the pressure at the glacier base.

20 When the basal temperature reaches $T_{m}$, the excess heat flux (incoming minus outgoing) at the base $\Delta q_{b}\left(\mathrm{~mW} \mathrm{~m}^{-2}\right)$ is absorbed as latent heat of fusion by the ice, and the melting rate $m$ is calculated as:

$m=\frac{\Delta q_{b}}{\rho L_{f}}$,

where $L_{f}=3.337 \times 10^{6} \mathrm{~J} \mathrm{~kg}^{-1}$ is the latent heat of ice. If $\Delta q_{b}<0$, the basal temperature decreases below the melting point, and melting stops.

The melted ice is subtracted from bottom of the ice column and reduces its thickness. The effect of melted ice on sliding is neglected. 
Clim. Past Discuss., doi:10.5194/cp-2016-116, 2016

Manuscript under review for journal Clim. Past

Published: 30 November 2016

(c) Author(s) 2016. CC-BY 3.0 License.

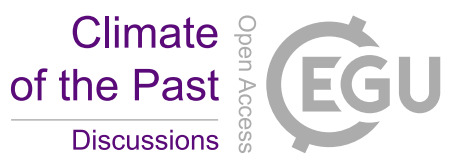

(c) (i)

\subsection{Glacier movement}

We calculated the vertical movement of the glacier with the 1-D ice flow model used in Parrenin et al. (2007b), which gives vertical velocity $u_{z}\left(\mathrm{~m} \mathrm{~s}^{-1}\right)$ as:

$u_{z}[z]=-\left(m+\left(a-\frac{\partial H}{\partial t}-m\right) \omega[\zeta]\right)$,

5 where $a\left(\mathrm{~m} \mathrm{~s}^{-1}\right)$ and $m\left(\mathrm{~m} \mathrm{~s}^{-1}\right)$ are respectively the accumulation (at the surface) and the melting (at the base) rates, and $H(\mathrm{~m})$ is the height of the glacier, expressed as ice equivalent. $\omega[\zeta]$ is the flux shape function (Parrenin et al., 2006), which depends on the non-dimensional vertical coordinate $\zeta=z / H$ and includes contributions of the basal sliding term and the shear deformation term:

$\omega[\zeta]=s \zeta+(1-s) \omega_{D}[\zeta]$

10 where $s$ is the sliding ratio (varying between 0 and 1) and $\omega_{D}[\zeta]$ is the vertical profile of deformation (Lliboutry, 1979), given by:

$\omega_{D}[\zeta]=1-\frac{p+2}{p+1}(1-\zeta)+\frac{1}{p+1}(1-\zeta)^{p+2}$,

where $p$ is the parameter determining the shear deformation component of the flux shape function. Lliboutry (1979) suggested that it is approximately given by:

$15 p=n-1+\frac{Q}{R T_{b}^{2}} G_{0} H$

where $n$ is the exponent of Glen's law from Eq. (4), $Q=6 \times 10^{4} \mathrm{~J} \mathrm{~mol}^{-1}$ is the activation energy, $R=8.3145 \mathrm{~J} \mathrm{~mol}^{-1} \mathrm{~K}^{-1}$ is the gas constant, $T_{b}$ is the basal temperature, and $G_{0}\left(\mathrm{~K} \mathrm{~m}^{-1}\right)$ is the vertical temperature gradient at the bottom of the ice column.

In Dome $\mathrm{C}$, using the values $n=3, G_{0}=21.62 \mathrm{~K} \mathrm{~km}^{-1}, H=3266 \mathrm{~m}$ and the current basal temperature $T_{b}=270.2 \mathrm{~K}$, we obtain a value $p \approx 9$. All the parameter values except $T_{b}$ and $H$ are assumed constant, and $p$ remains almost constant during the simulation. However, initial tests of the model using the theoretical formula from Eq. (15) were not able to produce thermal profiles close enough to the measured Dome C profile. Parrenin et al. (2007b) pointed out several reasons why this theoretical value of $p$ could be invalid at Dome $\mathrm{C}$, and estimated its value by inverse method obtaining $p=1.97 \pm 0.93$. Due to this uncertainty on the parameter $p$, we decided to set $p$ as a free parameter within a range $[0,9]$ for which we will try to obtain a probability distribution.

The value of the sliding parameter $s$ at Dome $\mathrm{C}$ is not well constrained, though Parrenin et al. (2007b) determined that it is less than 0.3 , and less than 0.1 with $50 \%$ confidence. However we do not include sliding as a free parameter, because sliding has a little effect on the thermal model and the calculated thermal profiles are much less sensitive to sliding than to the other parameters. This was verified in preliminary tests of the model taking sliding as a free parameter. For simplicity, we set the sliding parameter as a fixed value $s=0$. 
Clim. Past Discuss., doi:10.5194/cp-2016-116, 2016

Manuscript under review for journal Clim. Past

Published: 30 November 2016

(c) Author(s) 2016. CC-BY 3.0 License.

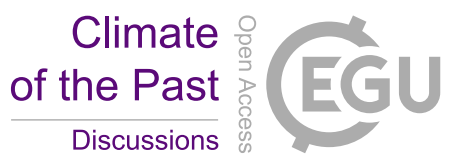

(c) (i)

\subsection{Shear heating}

Preliminary attempts to model the temperature profile at Dome $\mathrm{C}$ showed that the profile could not be fitted without some internal heat sources, that we assumed to be shear heating. The heat production by shear deformation $\Omega\left(\mu \mathrm{W} \mathrm{m}{ }^{-3}\right)$, or simply 'shear heating' is given as (see appendix C):

$5 \Omega=\frac{2}{A^{1 / n}}\left(\dot{\epsilon}_{z z}^{2}+\dot{\epsilon}_{x z}^{2}\right)^{\frac{n+1}{2 n}}$,

where $\dot{\epsilon}_{z z}$ is given by Eq. (A1) and $\dot{\epsilon}_{x z}$ is given by:

$\dot{\epsilon}_{x z}=\frac{1}{2} \frac{\partial u_{x}}{\partial z}=\frac{\bar{U}_{x}}{2 H} \omega^{\prime \prime}(\zeta)$,

where $\bar{U}_{x}$ is the average horizontal velocity. We calculate it as $\bar{U}_{x}=v_{\text {sur }} / \omega^{\prime}(1)$, where $v_{\text {sur }}$ is the ice velocity at the surface, relative to the bedrock. Estimates of ice velocity from geodetic surveys (Vittuari et al., 2004) at Dome C give a horizontal ice velocity of a few mm per year at the topographical dome, and $15 \pm 10 \mathrm{~mm} \mathrm{y}^{-1}$ at the drilling site by tying it to a $25 \mathrm{~km}$ away point. However, satellite measurements of ice velocity (Mouginot et al., 2012; Rignot et al., 2011) with a resolution of $450 \mathrm{~m}$ gave velocities of $\sim 13 \mathrm{~m} \mathrm{y}^{-1}$ at the four closest points to the drilling site. Tests with surface velocity in the order of $15 \mathrm{~mm} \mathrm{y}^{-1}$ yield a negligible shear heating, while the heating rate for a surface velocity on the order of $13 \mathrm{~m} \mathrm{y}^{-1}$ seems excessive and results in higher than observed curvature of the profile. In absence of reliable estimates of the ice surface velocity, we set it as a free parameter.

The influence of shear heating can be clearly seen in the heat flux profile (Fig. 5b). The heating rate is maximum at the bottom of the ice column and decreases upwards. For a given basal heat flux, shear heating gives a characteristic shape to the heat flux profile. The vertical distribution of shear heating is ultimately dependent on the flux shape function in Eq. (13), therefore dependent on the value of $p$ (Fig. 5b). This characteristic shape can be observed in the Dome C heat flux profile (Fig. 1), which shows a small but non negligible shear heating.

\subsection{Free parameters}

We have introduced four parameters that we consider free: the basal heat flux $q_{b}$, the parameter $p$, the ice surface velocity $v_{\text {sur }}$, and the ice-air temperature offset $T_{\text {offset }}$. For each set of parameter values, we calculate a temperature-depth profile with our advective-conductive model.

We select randomly the values of the parameters within a range of plausible values and calculate a temperature profile that we compare with the one measured at Dome C. For each combination of parameters, we calculate the misfits to temperature and heat flux profiles as the root mean square (RMS) difference between calculated and measured profiles. We retain a set of parameters if both misfits are below two respective maximum values or cutoffs for temperature and heat flux.

We set these cutoffs in such a way that we eliminate as many trials as possible, while keeping enough to obtain a meaningful statistic. We set the temperature cutoff to $0.5 \mathrm{~K}$ and the heat flux cutoff to $2 \mathrm{~mW} \mathrm{~m}^{-2}$. The procedure to obtain these cutoffs is discussed in the appendix B. 
Clim. Past Discuss., doi:10.5194/cp-2016-116, 2016

Manuscript under review for journal Clim. Past

Published: 30 November 2016

(c) Author(s) 2016. CC-BY 3.0 License.

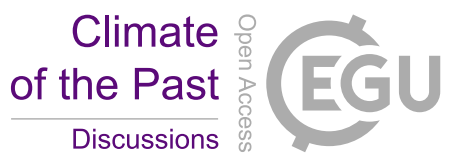

(c) (i)
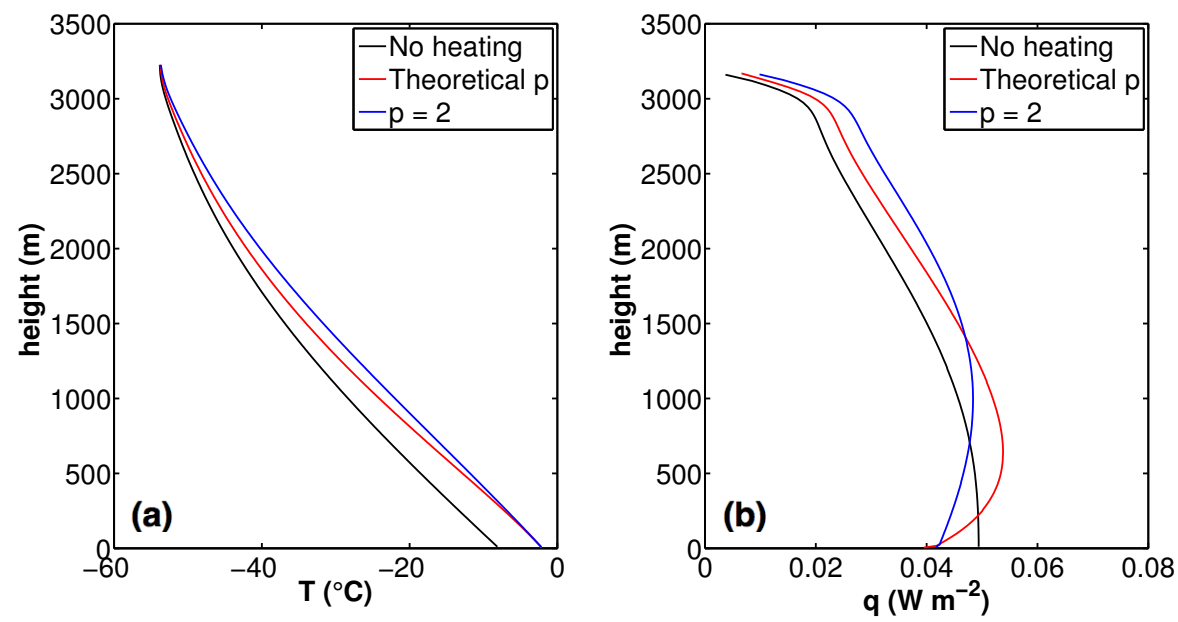

Figure 5. (a) Temperature-depth and (b) heat flux-depth profiles calculated with different vertical distributions of shear heating, determined by the value or the parameter $p$, for which we use the theoretical value (red) obtained from Eq. (15) and the value $p=2$ (blue) obtained by Parrenin et al. (2007b). Note how shear heating influences the shape of the heat flux profile. The other parameters for these calculations are $q_{b}=49.4 \mathrm{~mW} \mathrm{~m}^{-2}, v_{\text {sur }}=8 \mathrm{~m} \mathrm{y}^{-1}$, and $T_{\text {offset }}=0 \mathrm{~K}$. The no-heating experiment (black) uses the theoretical value $p \approx 9$ with shear heating set to 0 .

With both cutoffs as acceptance condition, we retained $\sim 0.18 \%$ of all trials, obtaining histograms of accepted values for each free parameter. The number of accepted experiments within a range of values of the free parameters defines a probability density, from which we derive the mean and standard deviation to obtain the most likely values and a $2 \sigma$ confidence interval.

\section{Initial conditions}

5 The initial temperature profile of Dome $\mathrm{C}$ at 800ka is impossible to determine from available data. However, because of the character of heat diffusion, the sensitivity of the temperature profile to the initial condition decreases with time. We performed several tests to confirm that the outcome of the simulations is independent of the initial temperature condition. We have thus used the same initial temperature profile for all simulations. This initial condition is obtained by applying the forward model to the present profile of Dome $\mathrm{C}$, using as boundary conditions the time reversed history of ice thickness, surface accumulation and SAT. The values of the free parameters are unknown for this backward in time simulation, but are not of critical importance because of the insensitivity to initial conditions. We chose basal heat flux $q_{b}=49.4 \mathrm{~mW} \mathrm{~m}^{-2}$ (the apparent heat flux), while for the parameter $p$, the surface velocity and the temperature offset we used $p=9, v=0 \mathrm{~m} \mathrm{y}^{-1}$ and $T_{\text {offset }}=0 \mathrm{~K}$. 

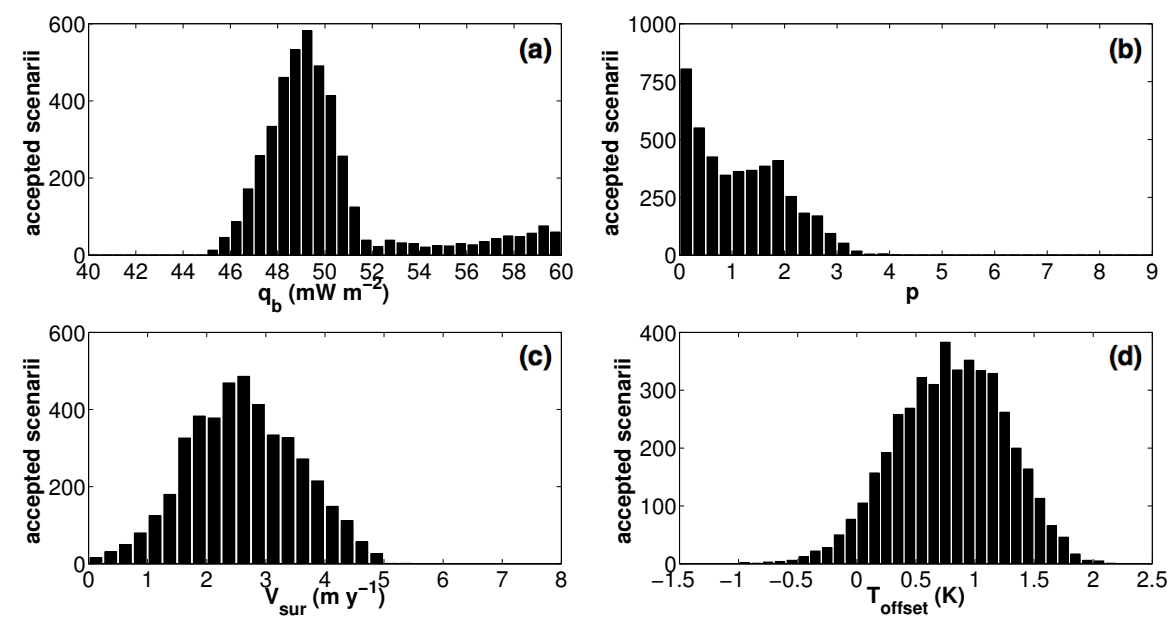

Figure 6. Histograms of retained values for the free parameters: (a) basal flux, (b) parameter $p$, (c) surface velocity, and (d) GST-SAT temperature offset.

\section{Results}

The histograms of retained values for each parameter are shown in Fig. 6. The peaks corresponding to the most likely values of the parameters are well marked suggesting that the parameters are well constrained, except for the parameter $p$. We can see how high values of $q_{b}$ are accepted, when in combination with low values of surface velocity (and therefore shear heating), but even very high $\left(\sim 60 \mathrm{~mW} \mathrm{~m}^{-2}\right)$ are accepted. This is happens due to melting, as high values of basal heat flux are able to keep the base of the glacier at fusion point through the whole simulation. Further increase in basal heat flux increase melting while the base of the glacier stays at melting temperature, having little effect on the resulting profiles.

The most probable value for the basal heat flux is $q_{b}=49.0 \pm 2.7 \mathrm{~mW} \mathrm{~m}^{-2}$, slightly lower than the apparent heat flux of $q_{b, a p p}=49.4 \pm 1.1 \mathrm{~mW} \mathrm{~m}^{-2}$ obtained from thermal conductivity and the thermal gradient at the bottom $300 \mathrm{~m}$ of the measured profile, stopped $60 \mathrm{~m}$ above the bedrock. We expected to obtain a slightly lower value than that of the apparent heat flux which includes a contribution from shear heating.

The parameter $p$ is not tightly constrained but low values of $p$ are more likely, with a $\sim 90 \%$ probability that $p$ is $<2.5$, and $\sim 50 \%$ probability that $p$ is $<1$.

The most likely surface velocity is $v_{\text {sur }}=2.6 \pm 1.9 \mathrm{~m} \mathrm{y}^{-1}$. This range is compatible with the surface velocity $\backsim 13 \mathrm{~m} \mathrm{y}^{-1}$ inferred from satellite measurements (Mouginot et al., 2012; Rignot et al., 2011), and results in substantial heat generation by shear deformation. The ice velocity measurements of $15 \pm 10 \mathrm{~mm} \mathrm{y}^{-1}$ from geodetic surveys (Vittuari et al., 2004) is too small to generate enough shear heating. As we assume a sliding ratio $s=0$ in our simulations, the surface velocity is the component corresponding to the shear deformation movement. The real surface velocity, sum of deformation and sliding components, is higher than the one obtained. 

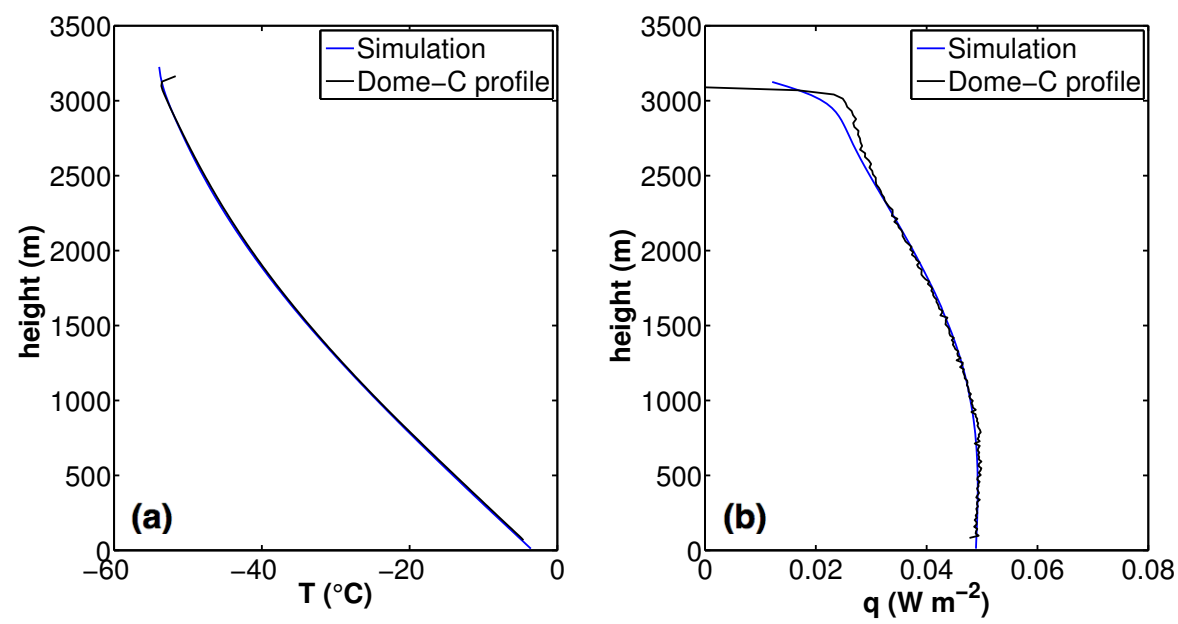

Figure 7. (a): Temperature-depth profile of Dome C (black) versus a simulation with parameter $p=1$ and the most likely values of the other parameters $q_{b}=49.03 \mathrm{~mW} \mathrm{~m}^{-2}, v_{\mathrm{sur}}=2.59 \mathrm{~m} \mathrm{y}^{-1}$ and $T_{\text {offset }}=0.815 \mathrm{~K}$ (blue). (b): Heat flux profile determined from the temperature profile, measured at Dome C (black) and calculated for the most likely values (blue).

The most likely temperature offset between the GST and the SAT is $T_{\text {offset }}=0.8 \pm 1.0 \mathrm{~K}$. This result could be affected by errors on the thickness of the firn layer, as well as on the SAT reconstruction itself.

We have recalculated the temperature profile with the most likely values, and a value $p=1$ for the parameter $p$ (Fig. 7). The good match of the measured and calculated temperature profiles supports that the basal heat flux and the shear heating are in

5 the correct range of values.

\section{Discussion and conclusions}

In this study, we have modelled the ice flow and heat transport at Dome $\mathrm{C}$ with a 1-D thermal and mechanical model, using the histories of air temperature, ice thickness and snow accumulation. We have tuned key parameters of ice flow and thermal boundary conditions so that the calculated temperature-depth profile fits the measured thermal profile at Dome $\mathrm{C}$, in order to obtain the most likely values of these parameters.

We have found that shear heating has a strong effect on our thermal model. Attempts to fit the temperature and heat flux profiles without taking shear heating into consideration yielded profiles determined by the thermal boundary conditions at the surface and the base of the glacier, i.e. SAT and basal heat flux. These factors alone failed to explain the shape of the temperature-depth profile. For the highest estimates of basal heat flux (obtained from the temperature gradient near the base) the temperature profiles were systematically $\sim 5 \mathrm{~K}$ colder than the one measured. Further tests showed that both temperature and heat flux profiles could be successfully fitted with a depth-uniform heating rate of $\sim 3.5 \mu \mathrm{W} \mathrm{m}{ }^{-3}$, but a uniform heating rate has no physical justification. 
Clim. Past Discuss., doi:10.5194/cp-2016-116, 2016

Manuscript under review for journal Clim. Past

Published: 30 November 2016

(c) Author(s) 2016. CC-BY 3.0 License.

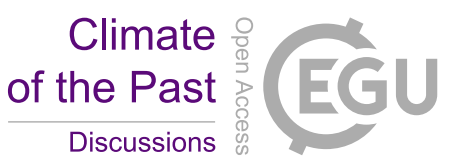

Shear heating is the only possible source of internal heating, but it varies with depth. The variation of shear heating with depth depends on the flux shape through Eq. (12). Therefore it is possible to extract information about the flux shape function because the goodness of the fit of the model to the profiles depends on it. The flux shape function is controlled by the parameter $p$, for which the theoretical formula (Eq. 15) predicts values on the order of $p \sim 9$. Initial tests with this theoretical value failed

5 to fit the Dome C profile satisfactorily, because shear heating was excessively concentrated in the lower part of the glacier. Parrenin et al. (2007b) argued that this formula is not be applicable to Dome C, and found the most likely value for this parameter $p=1.97 \pm 0.93$, based on a best fit of ice chronology to age markers. Although we have not been able to precisely determine the parameter $p$, our reconstruction suggests that the value of $p$ is likely to be closer to the value obtained by Parrenin et al. (2007b) than to the theoretical formula's range of values.

The deformation component of ice surface velocity, the parameter that defines the magnitude of shear heating, is reasonably well constrained. Accounting for the sliding ratio $s<0.3$ at Dome C (Parrenin et al., 2007b), the value of the ice surface velocity is of the same order as but lower than the values obtained by satellite measurements of ice velocity (Mouginot et al., 2012; Rignot et al., 2011) in the vicinity of Dome C. The estimates of ice velocity from geodetic surveys at Dome C (Vittuari et al., 2004) are too small to produce relevant shear heating.

The temperature offset is also well constrained, but it is an operational parameter that cannot be measured directly.

The basal heat flux value $49 \mathrm{~mW} \mathrm{~m}^{-2}$ is almost equal to the apparent heat flux near the base of the glacier, as expected because, without melting, the heat flux must be continuous. Because the apparent heat flux is estimated over $300 \mathrm{~m}$, it may be slightly affected by shear heating near the base of the glacier. There is a very good fit between the Dome $\mathrm{C}$ profile and the thermal profile determined by the most likely values we obtained for our parameters, suggesting that the values we obtained are correct. The crust below East-Antarctica is believed to be made up of Archean and Proterozoic terranes that were welded together in the mid-Proterozoic (Dalziel, 1992; Harley, 2003). The value of $49 \mathrm{~mW} \mathrm{~m}^{-2}$ obtained for the heat flux below Dome $\mathrm{C}$ is well within the range of values characteristic of Archean or Proterozoic terranes (Jaupart and Mareschal, 2015). In stable continents, local variations of surface heat flux do occur on different scales due to variations in crustal heat production (Jaupart et al., 2016). The heat flux value obtained is plausible and consistent with an estimate of heat flux beneath east Antarctica based on shear wave velocity profiles in the upper mantle (Shapiro and Ritzwoller, 2004). The latter estimate of average regional heat flux is insensitive to local heat flux variations. Although the upper part of the glacier may move over the bedrock by maybe as much as $100 \mathrm{~km}$ per 100,000 years, the lowermost oldest part of the glacier does not move if there is no slip and it has experienced a constant heat flux for a time much longer than the characteristic heat conduction time.

The thermal model allows us to calculate basal melting dynamically. While basal melting does not have a direct feedback on our model, it is an important basal parameter that controls sliding. Solutions were obtained with high values of basal heat flux (more than $65 \mathrm{~mW} \mathrm{~m}^{-2}$ ) that lead to constant melting temperature at the base. In this situation, increased basal heat flux can be absorbed by melting without affecting significantly the temperature profile. This has not been an issue in Dome $\mathrm{C}$, but the method will not work for determining basal heat flux if it is high enough to keep the base of the glacier at melting temperature, unless we introduce another constraint on the melting rate. For Dome $\mathrm{C}$ we can determine an upper limit to melting, as both glacier height and accumulation follow prescribed histories. This upper limit is never reached through the simulations. 
Clim. Past Discuss., doi:10.5194/cp-2016-116, 2016

Manuscript under review for journal Clim. Past

Published: 30 November 2016

(c) Author(s) 2016. CC-BY 3.0 License.

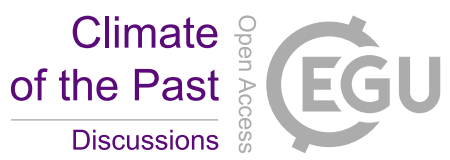

(c) (i)

\section{Acknowledgements}

Thanks to Catherine Ritz who provided us with the borehole temperature measurements.

This work was supported by grants from the Natural Sciences and Engineering Research Council of Canada Discovery grant (NSERC DG 140576948) and the Canada Research Program (CRC 230687) to H. Beltrami. H. Beltrami holds a Canada

5 Research Chair in Climate Dynamics. I. Hermoso de Mendoza is funded by a NSERC-CREATE Training Program in Climate Sciences based at St. Francis Xavier University.

\section{Appendix A: Numerical model}

The forward model simulates the thermal and mechanical processes at Dome $\mathrm{C}$ for the past $800 \mathrm{ky}$, the time period for which data of air temperature and snow accumulation are available. To numerically resolve the equations, we discretize time with a time-step $d t$ and discretize space by dividing the vertical ice column in homogeneous layers of variable thickness $\Delta z$. We have chosen a time-step of 1 year, which offers a resolution higher than that of the data on temperature and accumulation rates. Because we use an explicit scheme for solving the heat equation, the ice layers must be thicker than a minimum value to ensure the convergence of the solution.

\section{A1 Layer discretization and thinning}

We model the ice sheet at Dome $\mathrm{C}$ as an ice column discretized in layers of thickness $\Delta z$, which decreases in time. Given the vertical velocity $u_{z}[z]$, we can calculate the thinning of ice layers from the vertical strain rate $\dot{\epsilon}_{z z}$ :

$\dot{\epsilon}_{z z}=\frac{\partial u_{z}[z]}{\partial z}=-\frac{1}{H}\left(a-\frac{\partial H}{\partial t}-m\right) \omega^{\prime}[\zeta]$

where $\omega^{\prime}[\zeta]$ is the $\zeta$-derivative of the flux shape function in equation (13):

$\omega^{\prime}[\zeta]=s+(1-s) \omega_{D}^{\prime}[\zeta]$

where $s$ is the sliding ratio and the $\zeta$-derivative of the deformation component of the flux shape function:

$\omega_{D}^{\prime}[\zeta]=\frac{p+2}{p+1}\left(1-(1-\zeta)^{p+1}\right)$.

With the definition of $\dot{\epsilon}_{z z}$, the thickness $\Delta z$ of a layer at time $t+d t$ is computed as:

$\Delta z_{t+d t}=\Delta z_{t} \times\left(1+\dot{\epsilon}_{z z} d t\right)$.

The ice sheet grows continuously due to compaction of accumulated snow. We simulate this process by letting the top ice layer thicken with accumulation, and when reaching the maximal thickness of $60 \mathrm{~m}$, splitting it in two layers of equal thickness. On top of the ice layers we place a layer of firn, with a fixed thickness of $80 \mathrm{~m}$ and a density $75 \%$ that of ice. These values are estimated by averaging firn density data at Dome C (Arnaud et al., 2000). This layer is used for temperature calculations but 
Clim. Past Discuss., doi:10.5194/cp-2016-116, 2016

Manuscript under review for journal Clim. Past

Published: 30 November 2016

(c) Author(s) 2016. CC-BY 3.0 License.

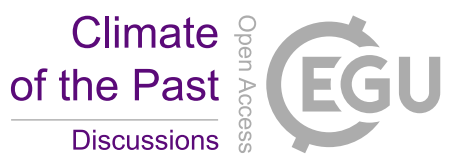

(c) (i)

it is not subject to mechanical thinning nor taken into account for flow calculations. Accumulation is added directly to the first ice layer directly below the firn layer, as we assume that, at the base, a mass of firn equal to the mass of snow accumulated at the top of the firn is instantly compacted into ice.

Through Eq. (A4) the thicknesses of the ice layers decrease in time and therefore in depth, becoming extremely thin at the

5 bottom. To ensure the convergence of heat conduction calculations, we merge neighbouring layers when their thickness drops below $15 \mathrm{~m}$.

Each ice layer is homogeneous and has temperature-dependent thermal properties. The dependence of thermal conductivity $\lambda\left(\mathrm{W} \mathrm{m}^{-1} \mathrm{~K}^{-1}\right)$ and specific heat $c_{p}\left(\mathrm{~J} \mathrm{~kg}^{-1} \mathrm{~K}^{-1}\right)$ on temperature for ice were taken from Handbook (2012), where values of $\lambda$ and $c_{p}$ for ice are tabulated for different temperatures. We fitted these values to polynomial functions, to have continuous functions. Thermal properties for the firn were taken from Jordan (1991).

\section{Appendix B: Method sensitivity}

As remarked before, we accept experiments when the misfit between the calculated and the measured profiles of both temperature and heat flux are below two cutoff values, that we set as $T_{\text {cutoff }}=0.5 \mathrm{~K}$ and $q_{\text {cutoff }}=2 \mathrm{~mW} \mathrm{~m}^{-2}$. The value for the peak for $q_{b}$ is weakly dependent on these values, but suffers big fluctuations when we accept too few experiments (for we don't have enough experiments to make a reliable statistic), and when accepting progressively more experiments we tend to a flat histogram.

For this reason, we want to set the value of the cutoffs as low as possible, otherwise the results would be meaningless. If the value is too small, the number of retained parameters will not populate a meaningful histogram. To decide the appropriate value, we examined how the value of the basal heat flux $q_{b}$ shifts with the value of the cutoffs. We can see this in Fig. A1 and Fig. A2.

As seen in Figs. A1 and A2, the variation of the heat flux peak position is minimal around the values $T_{\text {cutoff }}=0.5 \mathrm{~K}$ and $q_{\text {cutoff }}=2 \mathrm{~mW} \mathrm{~m}^{-2}$, therefore we selected these values as our cutoffs. To accept an experiment in our histogram, we require both misfits of temperature and heat flux to be below their respective cutoffs. Under these conditions, only $\sim 0.18 \%$ of more than 3 million trials are accepted, numerous enough to keep a reliable statistic and few enough to obtain meaningful results.

\section{Appendix C: Calculation of shear heating}

$\Omega\left(\mu \mathrm{W} \mathrm{m}^{-3}\right)$, the heat production due to shear deformation (Paterson, 1994), is given by:

$\Omega=\operatorname{tr}(\dot{\epsilon} \sigma)=\dot{\epsilon}_{x x} \sigma_{x}+\dot{\epsilon}_{y y} \sigma_{y}+\dot{\epsilon}_{z z} \sigma_{z}+2 \dot{\epsilon}_{x z} \tau_{x z}+2 \dot{\epsilon}_{y z} \tau_{y z}+2 \dot{\epsilon}_{x y} \tau_{x y}$

where $\tau_{x z}, \tau_{y z}$ and $\tau_{x y}$ are the shear-stress components and $\sigma_{x}, \sigma_{y}$ and $\sigma_{z}$ are the normal-stress components, being $x, y$ and $z$ (m) the two horizontal and the one vertical coordinates, respectively. The components of strain rate and the stress are related 
Clim. Past Discuss., doi:10.5194/cp-2016-116, 2016

Manuscript under review for journal Clim. Past

Published: 30 November 2016

(c) Author(s) 2016. CC-BY 3.0 License.

Climate

Discussions

(c) (i)

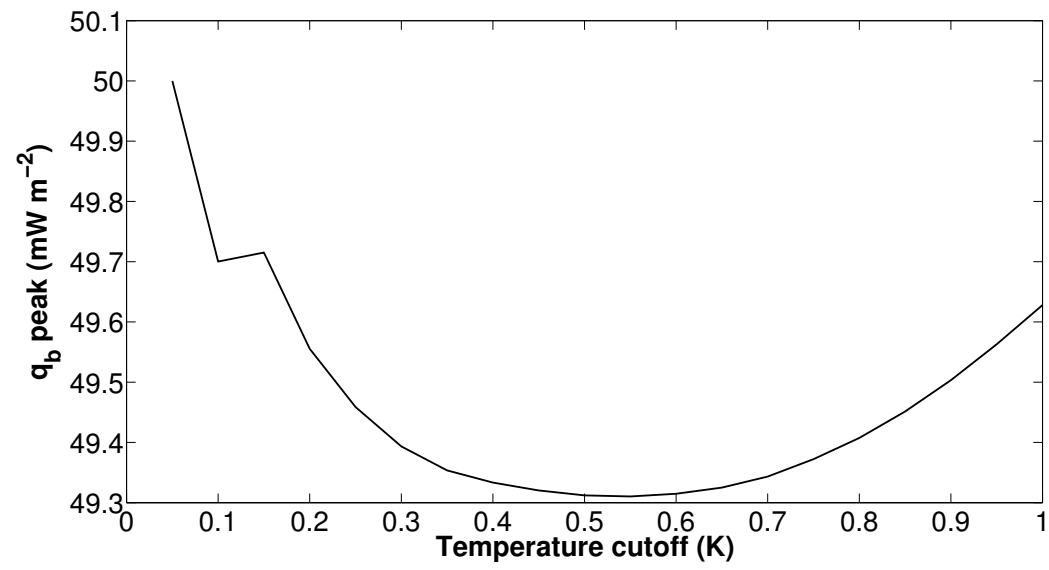

Figure A1. Change in the position of the $q_{b}$ peak, as function of the temperature cutoff $T_{\text {cutoff }}$. Heat flux cutoff was set to $q_{\text {cutoff }}=$ $2 \mathrm{~mW} \mathrm{~m}^{-2}$ to obtain this graphic.

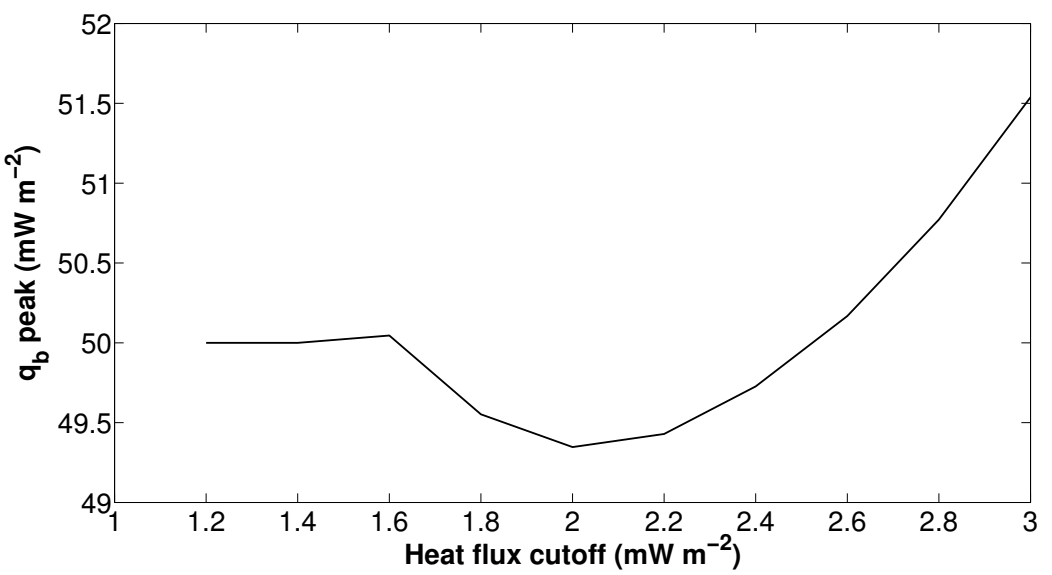

Figure A2. Change in the position of the $q_{b}$ peak, as function of the heat flux cutoff $q_{\text {cutoff }}$. Temperature cutoff was set to $T_{\text {cutoff }}=0.5 \mathrm{~K}$ to obtain this graphic.

through the Glen's law:

$\dot{\epsilon}_{x x}=\frac{\partial u_{x}}{\partial x}=A \tau^{n-1} \sigma_{x}^{\prime}$,

$\dot{\epsilon}_{x z}=\frac{1}{2}\left(\frac{\partial u_{x}}{\partial z}+\frac{\partial u_{z}}{\partial x}\right)=A \tau^{n-1} \tau_{x z}$

where $u_{i}\left(\mathrm{~m} \mathrm{~s}^{-1}\right)$ are the components of the ice velocity. $\sigma_{x}^{\prime}$ is defined as:

$5 \quad \sigma_{x}^{\prime}=\sigma_{x}-\frac{1}{3}\left(\sigma_{x}+\sigma_{y}+\sigma_{z}\right)$, 
Clim. Past Discuss., doi:10.5194/cp-2016-116, 2016

Manuscript under review for journal Clim. Past

Published: 30 November 2016

(c) Author(s) 2016. CC-BY 3.0 License.

and therefore:

$\sigma_{x}^{\prime}+\sigma_{y}^{\prime}+\sigma_{z}^{\prime}=0$

$\dot{\epsilon}_{x x}+\dot{\epsilon}_{y y}+\dot{\epsilon}_{z z}=\frac{\partial u_{x}}{\partial x}+\frac{\partial u_{y}}{\partial y}+\frac{\partial u_{z}}{\partial z}=0$.

In Eq. (C2) and Eq. (C4), $n=3$ is the Glen's exponent and $A\left(\mathrm{~Pa}^{-\mathrm{n}} \mathrm{s}^{-1}\right)$ is a quantity whose units depend on the Glen's exponent and that depends only on temperature:

$A=A_{0} \exp \left(-\frac{Q_{0}}{R T}\right)$,

where $A_{0}=3.985 \times 10^{-13} \mathrm{~Pa}^{-\mathrm{n}} \mathrm{s}^{-1}, Q_{0}=6 \times 10^{4} \mathrm{~J}_{\text {mole }}^{-1}$ is an activation energy, $R=8.3145 \mathrm{~J} \mathrm{~mole}^{-1} \mathrm{~K}^{-1}$ is the ideal gas constant, and $T(\mathrm{~K})$ is the absolute temperature.

The quantity $\tau$ is the effective shear stress, defined as:

$102 \tau^{2}={\sigma^{\prime}}_{x}^{2}+{\sigma^{\prime}}_{y}^{2}+{\sigma^{\prime}}_{z}^{2}+2\left(\tau_{x z}^{2}+\tau_{y z}^{2}+\tau_{x y}^{2}\right)$.

For the sake of simplicity, we assume a state of plane strain, with all components of velocity, strain and stress are independent of $y$, and their y-components $u_{y}=0, \dot{\epsilon}_{y y}=0$ and $\sigma_{y}=0$ are zero. Consequently, we have from Eq. (C4) and Eq. (C5):

$\sigma_{x}^{\prime}=-\sigma_{z}^{\prime}=\frac{1}{2}\left(\sigma_{x}-\sigma_{z}\right)$,

while Eq. (C6) and Eq. (C8) are reduced respectively to to:

$15 \dot{\epsilon}_{x x}+\dot{\epsilon}_{z z}=\frac{\partial u_{x}}{\partial x}+\frac{\partial u_{z}}{\partial z}=0$,

$\tau^{2}=\sigma_{x}^{\prime 2}+\tau_{x z}^{2}$.

With these simplifications, the heat production Eq. (C1) becomes:

$\Omega=\dot{\epsilon}_{x x} \sigma_{x}+\dot{\epsilon}_{z z} \sigma_{z}+2 \dot{\epsilon}_{x z} \tau_{x z}=2 \dot{\epsilon}_{x x} \sigma^{\prime}{ }_{x}+2 \dot{\epsilon}_{x z} \tau_{x z}$.

We can solve $\tau, \tau_{x z}$ and $\sigma_{x}^{\prime}$ from the Eqs. (C2), (C3) and (C11). It gives:

$20 \Omega=\frac{2}{A^{1 / n}}\left(\dot{\epsilon}_{z z}^{2}+\dot{\epsilon}_{x z}^{2}\right)^{\frac{n+1}{2 n}}$.

The value of $\dot{\epsilon}_{z z}$ is obtained from Eq. (A1). Assuming the ice flow to be laminar $\left(\frac{\partial u_{z}}{\partial x}=0\right), \dot{\epsilon}_{x z}$, Eq. (C2) is reduced to:

$\dot{\epsilon}_{x z}=\frac{1}{2}\left(\frac{\partial u_{x}}{\partial z}+\frac{\partial u_{z}}{\partial x}\right)=\frac{1}{2} \frac{\partial u_{x}}{\partial z}$.

The horizontal velocity $u_{x}$ is unknown, but it varies with depth (Parrenin et al., 2006) as:

$u_{x}=\bar{U}_{x} \omega^{\prime}(\zeta)$

25 where $\bar{U}_{x}$ is the average horizontal velocity at the surface of the glacier. Therefore, Eq. (C14) can be written as:

$\dot{\epsilon}_{x z}=\frac{1}{2} \frac{\partial u_{x}}{\partial z}=\frac{1}{2 H} \bar{U}_{x} \omega^{\prime \prime}(\zeta)$ 
Clim. Past Discuss., doi:10.5194/cp-2016-116, 2016

Manuscript under review for journal Clim. Past

Published: 30 November 2016

(c) Author(s) 2016. CC-BY 3.0 License.

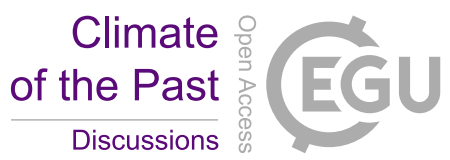

(c) (i)

\section{References}

Arnaud, L., Barnola, J. M., and Duval, P.: Physical modeling of the densification of snow/firn and ice in the upper part of polar ice sheets, Ann. Glaciol, 26, 39-44, 2000.

Augustin, L., Barbante, C., Barnes, P. R., Barnola, J. M., Bigler, M., Castellano, E., Cattani, O., Chappellaz, J., Dahl-Jensen, D., Delmonte, B., et al.: Eight glacial cycles from an Antarctic ice core, Nature, 429, 623-628, doi:10.1038/nature02599, 2004.

Barnola, J., Raynaud, D., Korotkevich, Y., and Lorius, C.: Vostok ice core provides 160,000-year record of atmospheric CO2, doi:10.1038/329408a0, 1987.

Carslaw, H. and Jaeger, J.: Heat conduction in solids, Oxford University Press, Oxford, p. 75, doi:10.1063/1.3057871, 1959.

Clark, P. U., Alley, R. B., and Pollard, D.: Northern Hemisphere ice-sheet influences on global climate change, Science, 286, 1104-1111, doi:10.1126/science.286.5442.1104, 1999.

Dahl-Jensen, D., Mosegaard, K., Gundestrup, N., Clow, G. D., Johnsen, S. J., Hansen, A. W., and Balling, N.: Past temperatures directly from the Greenland ice sheet, Science, 282, 268-271, doi:10.1126/science.282.5387.268, 1998.

Dalziel, I. W.: Antarctica: A tale of two supercontinents?, Annual Review of Earth and Planetary Sciences, 20, $501,1992$.

Fisher, A. T., Mankoff, K. D., Tulaczyk, S. M., Tyler, S. W., Foley, N., et al.: High geothermal heat flux measured below the West Antarctic Ice Sheet, Science advances, 1, e1500 093, doi:10.1126/sciadv.1500093, 2015.

Glen, J. W.: The creep of polycrystalline ice, in: Proceedings of the Royal Society of London A: Mathematical, Physical and Engineering Sciences, vol. 228, pp. 519-538, The Royal Society, doi:10.1098/rspa.1955.0066, 1955.

Goujon, C., Barnola, J.-M., and Ritz, C.: Modeling the densification of polar firn including heat diffusion: Application to close-off characteristics and gas isotopic fractionation for Antarctica and Greenland sites, Journal of Geophysical Research: Atmospheres, 108, doi:10.1029/2002JD003319, 2003.

Handbook, C.: CRC Handbook of Chemistry and Physics 2012-2013, 2012.

Harley, S.: Archaean-Cambrian crustal development of East Antarctica: metamorphic characteristics and tectonic implications, Geological Society, London, Special Publications, 206, 203-230, doi:10.1144/GSL.SP.2003.206.01.11, 2003.

Jaupart, C. and Mareschal, J.: Heat flow and thermal structure of the lithosphere, Treatise on Geophysics, 6, 217-252, doi:10.1016/B978-0444-53802-4.00114-7, 2015.

Jaupart, C., Mareschal, J., and Iarotsky, L.: Radiogenic heat production in the continental crust, Lithos, 262, 398-427, doi:10.1016/j.lithos.2016.07.017, 2016.

Johnsen, S. J., Dahl-Jensen, D., Dansgaard, W., and Gundestrup, N.: Greenland palaeotemperatures derived from GRIP bore hole temperature and ice core isotope profiles, Tellus B, 47, 624-629, doi:10.1034/j.1600-0889.47.issue5.9.x, 1995.

30 Jordan, R.: A one-dimensional temperature model for a snow cover: Technical documentation for SNTHERM. 89., Tech. rep., DTIC Document, http://acwc.sdp.sirsi.net/client/en_US/search/asset/1011960;jsessionid=0DD89186E5D788FB1D334F4331245C4D. enterprise-15000, 1991.

Jouzel, J.: EPICA Dome C Ice Core 800KYr Deuterium Data and Temperature Estimates, ftp.ncdc.noaa.gov/pub/data/paleo/icecore/ antarctica/epica_domec/edc3deuttemp2007.txt, 2007.

35 Jouzel, J., Masson-Delmotte, V., Cattani, O., Dreyfus, G., Falourd, S., Hoffmann, G., Minster, B., Nouet, J., Barnola, J.-M., Chappellaz, J., et al.: Orbital and millennial Antarctic climate variability over the past 800,000 years, science, 317, 793-796, doi:10.1126/science.1141038, 2007. 
Clim. Past Discuss., doi:10.5194/cp-2016-116, 2016

Manuscript under review for journal Clim. Past

Published: 30 November 2016

(c) Author(s) 2016. CC-BY 3.0 License.

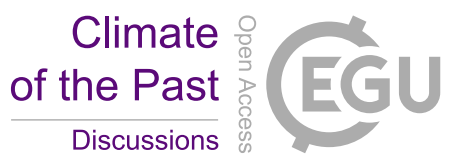

(c) (i)

Lliboutry, L.: A critical review of analytical approximate solutions for steady state velocities and temperature in cold ice-sheets, 1979.

Marshall, S. J.: Recent advances in understanding ice sheet dynamics, Earth and Planetary Science Letters, 240, 191-204, doi:10.1016/j.eps1.2005.08.016, 2005.

Mouginot, J., Scheuchl, B., and Rignot, E.: Mapping of ice motion in Antarctica using synthetic-aperture radar data, Remote Sensing, 4, 2753-2767, doi:10.3390/rs4092753, 2012.

Oppenheimer, M.: Global warming and the stability of the West Antarctic Ice Sheet, Nature, 393, 325-332, doi:10.1038/30661, 1998.

Parrenin, F., Remy, F., Ritz, C., Siegert, M. J., and Jouzel, J.: New modeling of the Vostok ice flow line and implication for the glaciological chronology of the Vostok ice core, Journal of Geophysical Research: Atmospheres, 109, doi:10.1029/2004JD004561, 2004.

Parrenin, F., Hindmarsh, R., and Rémy, F.: Analytical solutions for the effect of topography, accumulation rate and lateral flow divergence on isochrone layer geometry, Journal of Glaciology, 52, 191-202, doi:10.3189/172756506781828728, 2006.

Parrenin, F., Barnola, J.-M., Beer, J., Blunier, T., Castellano, E., Chappellaz, J., Dreyfus, G., Fischer, H., Fujita, S., Jouzel, J., et al.: The EDC3 chronology for the EPICA Dome C ice core, Climate of the Past, 3, 485-497, doi:10.5194/cpd-3-575-2007, 2007a.

Parrenin, F., Dreyfus, G., Durand, G., Fujita, S., Gagliardini, O., Gillet, F., Jouzel, J., Kawamura, K., Lhomme, N., Masson-Delmotte, V., et al.: 1-D-ice flow modelling at EPICA Dome C and Dome Fuji, East Antarctica, Climate of the Past, 3, 243-259, doi:10.5194/cp-3-2432007, 2007b.

Paterson, W.: The physics of glaciers, Butterworth-Heinemann, doi:10.1002/(SICI)1096-9837(199610)21:10<980::AID-ESP586>3.0.CO;2G, 1994.

Petit, J.-R., Jouzel, J., Raynaud, D., Barkov, N. I., Barnola, J.-M., Basile, I., Bender, M., Chappellaz, J., Davis, M., Delaygue, G., et al.: Climate and atmospheric history of the past 420,000 years from the Vostok ice core, Antarctica, Nature, 399, 429-436, doi:10.1038/20859, 1999.

Pol, K., Masson-Delmotte, V., Johnsen, S., Bigler, M., Cattani, O., Durand, G., Falourd, S., Jouzel, J., Minster, B., Parrenin, F., et al.: New MIS 19 EPICA Dome $\mathrm{C}$ high resolution deuterium data: Hints for a problematic preservation of climate variability at sub-millennial scale in the "oldest ice", Earth and Planetary Science Letters, 298, 95-103, doi:10.1016/j.eps1.2010.07.030, 2010.

Rignot, E., Mouginot, J., and Scheuchl, B.: MEaSUREs InSAR-Based Antarctica Velocity Map, NASA EOSDIS DAAC at NSIDC: Boulder, CO, USA, http://nsidc.org/data/nsidc-0484.html, 2011.

Ritz, C., Rommelaere, V., and Dumas, C.: Modeling the evolution of Antarctic ice sheet over the last 420,000 years: Implications for altitude changes in the Vostok region, Journal of Geophysical Research: Atmospheres, 106, 31 943-31 964, doi:10.1029/2001JD900232, 2001.

Ruth, U., Barnola, J.-M., Beer, J., Bigler, M., Blunier, T., Castellano, E., Fischer, H., Fundel, F., Huybrechts, P., Kaufmann, P., et al.: "EDML1": a chronology for the EPICA deep ice core from Dronning Maud Land, Antarctica, over the last 150000 years, Climate of the Past Discussions, 3, 549-574, doi:10.5194/cp-3-475-2007, 2007.

Shapiro, N. M. and Ritzwoller, M. H.: Inferring surface heat flux distributions guided by a global seismic model: particular application to Antarctica, Earth and Planetary Science Letters, 223, 213-224, doi:10.1016/j.eps1.2004.04.011, 2004.

Spahni, R., Chappellaz, J., Stocker, T. F., Loulergue, L., Hausammann, G., Kawamura, K., Flückiger, J., Schwander, J., Raynaud, D., MassonDelmotte, V., et al.: Atmospheric methane and nitrous oxide of the late Pleistocene from Antarctic ice cores, Science, 310, 1317-1321, doi:10.1126/science.1120132, 2005.

Tabacco, I., Passerini, A., Corbelli, F., and Gorman, M.: Determination of the surface and bed topography at Dome C, East Antarctica, Journal of Glaciology, 44, 185-191, 1998. 
Clim. Past Discuss., doi:10.5194/cp-2016-116, 2016

Manuscript under review for journal Clim. Past

Published: 30 November 2016

(c) Author(s) 2016. CC-BY 3.0 License.

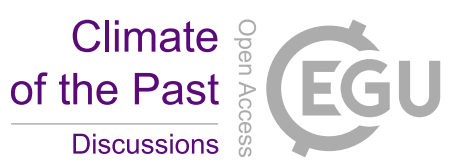

(c) (1)

Vittuari, L., Vincent, C., Frezzotti, M., Mancini, F., Gandolfi, S., Bitelli, G., and Capra, A.: Space geodesy as a tool for measuring ice surface velocity in the Dome C region and along the ITASE traverse, Annals of Glaciology, 39, 402-408, doi:10.3189/172756404781814627, 2004.

Vostok, S.: Federal Program 'World Ocean'. Antartic Research and Investigation, http://www.aari.aq, 1958-2016.

5 Watanabe, O., Kamiyama, K., Motoyama, H., Fujii, Y., Shoji, H., and Satow, K.: The paleoclimate record in the ice core at Dome Fuji station, East Antarctica, Annals of Glaciology, 29, 176-178, doi:10.3189/172756499781821553, 1999. 